\title{
Research on China's Regional Carbon Emission Quota Allocation in 2030 under the Constraint of Carbon Intensity
}

\author{
Yuan Zhang $\mathbb{D}$ \\ School of Management, China University of Mining \& Technology (Beijing), Beijing 100083, China \\ Correspondence should be addressed to Yuan Zhang; zhangyuan@student.cumtb.edu.cn
}

Received 9 September 2020; Revised 13 November 2020; Accepted 13 November 2020; Published 27 November 2020

Academic Editor: Georgios I. Giannopoulos

Copyright (c) 2020 Yuan Zhang. This is an open access article distributed under the Creative Commons Attribution License, which permits unrestricted use, distribution, and reproduction in any medium, provided the original work is properly cited.

\begin{abstract}
To achieve the goal of carbon dioxide emission reduction in 2030 promised to the United Nations, China unified the Carbon Trading System (CTS) in 2017 since carbon dioxide quota allocation is one of the core issues of carbon trading. It is imperative to establish a flexible carbon quota allocation system based on the unbalanced characteristics of resource endowment and economic development in different regions. Unlike previous distribution research, this paper considers five principles, which are fairness principle, efficiency principle, feasibility principle, development principle, and innovation principle. The maximum deviation method is used to research the carbon emission quota allocation in 30 provinces of China, and the results are compared with those under the single principle and the information entropy method. The results reveal that the distribution under the single principle is severely unbalanced, making the region have a strong sense of relative deprivation. The maximum deviation method is better than the information entropy method to achieve carbon intensity by 2030 . It is also conducive to promote the coordinated development of the regional economy, narrow the poverty gap, and achieve sustainable development.
\end{abstract}

\section{Introduction}

According to the World Energy Statistics Yearbook in 2018, the global energy consumption increased by $2.9 \%$, while the carbon emissions generated by energy consumption increased by $2 \%$, reaching the highest level since 2010 . Twothirds of the growth came from China, the United States, and India [1]. According to the Environment Emissions Gap Report in 2019, considering the emission reduction commitments submitted by various countries, the global temperature still rises by $3.2^{\circ} \mathrm{C}$ by the end of this century. The global carbon emission is reduced by $7.6 \%$ annually from 2020 to 2030 to achieve the temperature control target of $1.5^{\circ} \mathrm{C}$. In response to global climate change, as the largest developing country, the Chinese government proposes to peak carbon dioxide emissions by 2030 and promises to reduce carbon dioxide emission intensity by $60 \%-65 \%$ compared with 2005.

China faces more challenges of enormous carbon emission reduction in the future [2]. Based on the pressure of carbon emission reduction and the realistic factors of domestic economic transformation, the " $13^{\text {th }}$ Five-Year" Plan documents (2016-2020) point out that it is necessary to establish a sound carbon emission distribution system and allocate the initial carbon quota reasonably [3]. Due to the resource endowments and the imbalance of economic development in different regions, all provinces must make joint efforts to achieve carbon emission reduction. The allocation of carbon quotas in all areas of China should follow the principle of "common but differentiated responsibilities" [4]. Therefore, the carbon quota design, which is suitable for different regions, is the key to China's carbon emission reduction. The rationality of provincial carbon quota allocation, based on total amount control, is the key to achieve the carbon emission reduction target by 2030 [5]. The rationality of the allocation of carbon emission quota in different regions depends on the effect of total amount control. Many scholars have studied the initial allocation of carbon emission quota in different areas.

Different methods and models have been used in the research of carbon quota allocation, which can be divided into the following categories. The first category is using the 
model method to allocate carbon quota. Dong et al. considered the fairness and efficiency simultaneously and used the Fixed Cost Allocation Model to allocate carbon quota at the provincial level [6]. Song et al. aimed at maximizing the overall average efficiency and used the Fixed Cost Allocation Model (FCAM) to study the provincial carbon emission allocation in 2020 [7]. Zhou et al. built a Data Envelopment Analysis (DEA) model to distribute the carbon quota of each province [8]. Wang et al. and Miao et al. adopted the improved Zero-Sum Gains Data Envelopment Analysis (ZSGDEA) optimization model and proposed a practical scheme for the provincial carbon emission quota allocation. The results showed that different quota targets and different emission reduction burdens should be formulated $[9,10]$. Zhang et al. used the DEA model to study carbon quota allocation in China's industrial industries [11]. Yu et al. introduced the improved fuzzy clustering and Shapley value decomposition method to allocate the provincial carbon emission reduction targets in China [12]. Zhang et al. proposed policy suggestions for the carbon quota allocation in different regions by comparing the Shapley value and entropy method [13]. Based on Shapley's value, three power plants in Shanghai are taken as research cases by Liao et al. to simulate their initial quota allocation and compared with the baseline method and grandfather method, which prove that the Shapley value allocation results are fairer [14]. Chen et al. and Zhou et al. have adopted the Analytic Hierarchy Process (AHP) method to study the carbon quota of various industrial sectors in China $[15,16]$.

The other category is in terms of using a single index and the composite index. Zhou et al. used five individual indexes for distribution research, and the results showed that the distributions of carbon emissions and the population were more equitable [17]. Mu et al. considered multiple indicators such as Marginal Abatement Cost Curve (MACC), population, Gross Domestic Product (GDP), and energy consumption and concluded that MACC is the most effective and fair factor [18]. Chen et al. studied the effect of carbon quota allocation in each province based on the composite index method. The results showed that energy consumption intensity had the most significant impact on carbon quota [19]. Park et al. established a new Boltzmann distribution model of population, per capita carbon emissions, and carbon dioxide emissions [20]. Han et al. used the direction distance function to establish the composite index to allocate the carbon quota in Beijing-Tianjin-Hebei. The results showed that carbon emission was the main factor affecting carbon quota [21]. To ensure the fairness of distribution, $\mathrm{Li}$ et al. studied the carbon emissions of different regions from the perspective of multiple indicators of per capita GDP and per capita historical cumulative carbon emissions [22]. From the standpoint of equity, Yang Chao et al. used five composite indicators of equal output, equal per capita, equal space, historical carbon emissions, and carbon sink capacity to study the distribution of China's carbon emission quota in 2017 [23]. Wang and Zhao studied the allocation of provincial carbon initial quota based on the improved equal proportion distribution method and information entropy method [24]. Li et al. selected three indicators of population, GDP, and historical carbon emissions, combined with the maximum deviation method (MDM) method, and achieved excellent results in the study of carbon quota distribution in the Pearl River Delta [25]. Wang et al. and Li et al. selected several indicators, respectively, using the Technique for Order Preference by Similarity to an Ideal Solution (TOPSIS) method and Boltzmann distribution method to study the carbon emission quota distribution of Chinese provinces, and provide policy suggestions for the national carbon emission distribution scheme $[26,27]$.

According to the prediction of the China Energy Research Association, nonfossil energy consumption accounts for about $20 \%$ of energy consumption, and the urbanization level reaches $70 \%$ by 2030 . In addition to common factors such as population, GDP, and urbanization level, the transformation of energy structure and industrial structure also significantly impacts future carbon emissions [28]. Therefore, except for the traditional population (fairness principle) and GDP (efficiency principle), this paper also considers the impact of carbon emissions produced by the primary end energy consumption (feasibility principle), urbanization rate (development principle), and proportion of the tertiary industry (innovation principle) on the distribution of regional carbon emissions in China. As the research of Zhou and Wang shows that none of the four main methods of $\mathrm{CO}_{2}$ emission distribution is the best, each has its advantages and disadvantages. The index method is one of the most common and easy to understand manner [29]. Therefore, in this paper, the index method is used to analyze the initial carbon quota allocation among provinces under the constraint of carbon intensity in 2030. The maximum deviation method (MDM) is used to establish the optimization attribute weight model, which effectively solves mixed multiattribute decision-making. A comparative analysis is made about the MDM method, the single index method, and the improved information entropy method (IEM). The results show that the MDM method has higher distribution efficiency, which is significant to achieve the emission reduction target by 2030, narrow the regional economic gap, promote the development of underdeveloped areas, and promote technological innovation. At the same time, a reference for the unification of the national carbon market is also provided in this paper.

\section{Materials and Methods}

\subsection{Index Selection and Selection Basis}

2.1.1. Principle of Equality. As early as 1990, Rose [30] had emphasized that everyone in the world has equal access to atmospheric resources and pollutants. The allocation of $\mathrm{CO}_{2}$ emissions quotas based on the population has been widely applied [31]. The number of permanent residents in different regions has a direct impact on carbon emissions. Therefore, considering the fairness principle, more population areas 
should be given more carbon quotas appropriately and vice versa. In this paper, the number of permanent residents in each province is taken as the index of the equality principle. The data are obtained from the China Statistical Yearbook (2006-2018).

2.1.2. Principle of Efficiency. Bohm et al. [32] believed that distribution, according to market efficiency, is the best choice. Without considering the distribution of regional emission efficiency differences, the phenomenon of "whipping fast cattle" occurs [33]. Phylipsen et al. [34] put forward the allocation of emissions based on GDP. This principle can effectively reduce the impact of emission reduction on economic development. Reasonable distribution helps to reduce regional economic differences and promote the coordinated development of the regional economy. In this paper, the data are expressed in terms of the prices of 2005, and the data are derived from the China Statistical Yearbook (2006-2018). Assuming that the average annual GDP growth rates in 2018-2020, 2020-2025, and 2025-2030 are $6.5 \%, 5.5 \%$, and $4.5 \%$, respectively, the GDP in $2030 \mathrm{can}$ be calculated.

2.1.3. Principle of Feasibility. Energy consumption can produce generous dioxide, and the types of energy consumption vary significantly in different regions. Many scholars analyzed the impact of final energy consumption on carbon emissions $[35,36]$. This paper sorts out eight principal energy consumption (coal, coke, crude oil, gasoline, kerosene, diesel oil, fuel oil, and natural gas) in different regions. The cumulative carbon emissions in different regions are calculated using the methods provided by IPCC [37]. The formula is as follows:

$$
C_{j}=\sum_{i=1}^{8} E_{j i} * K_{i 1} * K_{i 2},
$$

where $C_{j}$ expresses the total carbon dioxide emission of region $j, E_{i}$ represents the consumption of energy $i$ in region $j$; and $K_{1}, K_{2}$ indicate the standard coal conversion coefficient and carbon emission coefficient, respectively. As shown in Table 1, the eight principal energy consumptions are derived from China Energy Statistical Yearbook (2006-2018).

2.1.4. Principle of Development. Advancing urbanization in a reasonable and orderly manner and developing a lowcarbon economy is an important challenge many countries face. Many scholars have studied how much impact does urbanization has on energy consumption and carbon emissions in different regions, such as the provincial level and city level [38-40]. The results show that urbanization in different regions can promote or inhibit carbon emissions. Therefore, considering the development of different regions, the urbanization rate is introduced into the carbon quota allocation as an indicator of the development principle. The urbanization rate is derived from the ratio of the urban population to the permanent population in each region. The related data are received from the China Statistical Yearbook (2006-2018).

2.1.5. Principle of Innovation. As China is still a developing country, the proportion of tertiary industry in China is much smaller than that in developed countries. However, technological innovation is conducive to curbing carbon emissions. The empirical research results of many Chinese scholars show that the development of the tertiary industry will reduce regional carbon emissions, which is conducive to promoting regional development $[41,42]$. Therefore, based on previous studies, this paper selects the proportion of tertiary industry as the index of technological innovation to allocate regional carbon quota more reasonably. It is expressed by the ratio of the actual output value of the tertiary industry to the real GDP. The data are collected from the China Statistical Yearbook (2006-2018).

\subsection{Allocation of Carbon Quota Increment under the Single} Index. According to the target of the carbon intensity in 2030 , it is assumed that the carbon intensity in 2030 decreased by $65 \%$ compared to 2005 . According to the calculation formula of carbon intensity, the carbon intensity in yeart can be defined as

$$
\begin{aligned}
\mathrm{CI}_{t} & =\frac{Q_{t}}{\mathrm{GDP}_{t}}, \\
\mathrm{CI}_{2030} & =(1-65 \%) * \mathrm{CI}_{2005},
\end{aligned}
$$

where $\mathrm{CI}_{t}$ is the carbon intensity in yeart, $Q_{t}$ is the carbon dioxide emissions in year $t$, and $\mathrm{GDP}_{t}$ represents GDP in year $t$. Through formulas (2) and (3), the carbon intensity and carbon emission in 2030 can be obtained, and the carbon emission increment from 2005 to 2030 can be calculated as follows:

$$
\begin{aligned}
Q_{2030} & =\mathrm{CI}_{2030} * \mathrm{GDP}_{2030}, \\
\Delta Q & =Q_{2030}-Q_{2005},
\end{aligned}
$$

where $\mathrm{CI}_{2030}, \mathrm{CI}_{2005}$, respectively, represent the carbon emission intensity in 2030 and $2005, Q_{2030}$ represents the carbon emission in 2030, and $\Delta Q$ represents the carbon dioxide emission increment in 2030 compared with 2005. It is assumed that the incremental allocation of carbon quota of each province under each indicator is calculated by taking the percentage of each province's five indicators in the national total from 2005 to 2017 :

$$
\begin{aligned}
\Delta Q_{i 1} & =\frac{\sum_{t=2005}^{2017} P_{i_{(t)}}}{\sum_{i=1}^{30} \sum_{t=2005}^{2017} P_{i_{(t)}}} * \Delta Q, \\
\Delta Q_{i 2} & =\frac{\sum_{t=2005}^{2017} \mathrm{GDP}_{i_{(t)}}}{\sum_{i=1}^{30} \sum_{t=2005}^{2017} \mathrm{GDP}_{i_{(t)}}} * \Delta Q,
\end{aligned}
$$


TABLE 1: The correlation coefficient.

\begin{tabular}{lcccccccc}
\hline Coefficient type & Coal & Coke & Crude oil & Gasoline & Kerosene & Diesel oil & Fuel oil & Natural gas \\
\hline$K_{1}$ & 0.7559 & 0.8550 & 0.5857 & 0.5538 & 0.5714 & 0.5921 & 0.6185 \\
$K_{2}$ & 0.7143 & 0.9714 & 1.4286 & 1.4174 & 1.4174 & 1.4571 & 1.4286 & 1.3300 \\
\hline
\end{tabular}

$$
\begin{gathered}
\Delta Q_{i 3}=\frac{\sum_{t=2005}^{2017} C_{i_{(t)}}}{\sum_{i=1}^{30} \sum_{t=2005}^{2017} C_{i_{(t)}}} * \Delta Q, \\
\Delta Q_{i 4}=\frac{\sum_{t=2005}^{2017} \mathrm{UR}_{i_{(t)}}}{\sum_{i=1}^{30} \sum_{t=2005}^{2017} \mathrm{UR}_{i_{(t)}}} * \Delta Q, \\
\Delta Q_{i 5}=\frac{\sum_{t=2005}^{2017} T_{i_{(t)}}}{\sum_{i=1}^{30} \sum_{t=2005}^{2017} T_{i_{(t)}}} * \Delta Q,
\end{gathered}
$$

where $P_{i_{(t)}}, \mathrm{GDP}_{i_{(t)}}, C_{i_{(t)}}, \mathrm{UR}_{i_{(t)}}$, and $T_{i_{(t)}}$ represent the five single indicators of population, GDP, carbon emissions, urbanization rate, and the proportion of tertiary industry in the $t$ year of $i$ province, respectively. $\Delta Q_{i 1} \Delta Q_{i 2} \Delta Q_{i 3}, \Delta Q_{i 4}$, and $\Delta Q_{i 5}$ represent the increased carbon emission quota allocation of $i$ area under the five single indicators, respectively, $i=1,2,3, \ldots, 30, j=1,2,3,4,5$.

\subsection{Allocation of Carbon Quota Increment under the Maxi-} mum Deviation Method. According to the characteristics of unbalanced regional development in China, single principle distribution produces a strong sense of relative deprivation in different regions, which is not conducive to fair and effective dissemination and sustainable economic development. Based on the results of five single indicators, this study uses MDM to build a comprehensive index to allocate the carbon quota increment of each province. Matrix $\mathrm{A}$ is calculated according to formulas (6)-(10):

$$
A=\left[\begin{array}{ccccc}
\Delta Q_{11} & \Delta Q_{12} & \Delta Q_{13} & \Delta Q_{14} & \Delta Q_{15} \\
\Delta Q_{21} & \Delta Q_{22} & \Delta Q_{23} & \Delta Q_{24} & \Delta Q_{25} \\
\vdots & \vdots & \vdots & \vdots & \vdots \\
\vdots & \vdots & \vdots & \vdots & \vdots \\
\Delta Q_{i 1} & \Delta Q_{i 2} & \Delta Q_{i 3} & \Delta Q_{i 4} & \Delta Q_{i 5}
\end{array}\right]
$$

According to the values in matrix $A$, the difference of carbon quota increment of each two provinces under the indicator $j$ is calculated:

$$
\begin{aligned}
h_{i j k} & =\left|\Delta Q_{i j}-\Delta Q_{k j}\right|, \\
H_{i k} & =\sum_{j=1}^{5} W_{j}\left|\Delta Q_{i j}-\Delta Q_{k j}\right|, \\
H & =\sum_{i=1}^{30} \sum_{k=1}^{30} \sum_{j=1}^{5} W_{j}\left|\Delta Q_{i j}-\Delta Q_{k j}\right|,
\end{aligned}
$$

where $h_{i j k}$ represents the absolute deviation of the incremental allocation of carbon quota between $i$ and $k$ provinces under each single index $j . H_{i k}$ represents the sum of the absolute deviation of the incremental allocation of carbon quota between $i$ and $k$ areas under the five indicators, $k=1,2,3, \ldots, 30$. Hrepresents the sum of the absolute deviation between 30 provinces under five indicators. The maximum value of the square sum of deviations among 30 areas under the five single indicators is found out, using the maximum deviation method, expressed as $\max H$. The weight of each index $W_{j}$ is calculated according to the Lagrange method, where $\sum_{j=1}^{5} W_{j}^{2}=1, W_{j}>0$ :

$$
\begin{gathered}
\max H=\sum_{i=1}^{30} \sum_{k=1}^{30} \sum_{j=1}^{5} W_{i}\left|\Delta Q_{i j}-\Delta Q_{k j}\right|^{2}, \\
W_{j}=\frac{\sum_{i=1}^{30} \sum_{k=1}^{30}\left|\Delta Q_{i j}-\Delta Q_{k j}\right|}{\sqrt{\sum_{j=1}^{5}\left(\sum_{i=1}^{30} \sum_{k=1}^{30}\left|\Delta Q_{i j}-\Delta Q_{k j}\right|\right)^{2}}},
\end{gathered}
$$

And then normalize $W_{j}$ to get the final weight $w_{j}^{*}$ corresponding to each index:

$$
w_{j}^{*}=\frac{\sum_{i=1}^{30} \sum_{k=1}^{30}\left|\Delta Q_{i j}-\Delta Q_{k j}\right|}{\sum_{j=1}^{5} \sum_{i=1}^{30} \sum_{k=1}^{30}\left|\Delta Q_{i j}-\Delta Q_{k j}\right|}
$$

where $w_{j}^{*}>0, \sum_{j=1}^{5} w_{j}^{*}=1$. Therefore, the increment of carbon quota in province $i$ can be expressed as

$$
\Delta Q_{i}=w_{1}^{*} \Delta Q_{i 1}+w_{2}^{*} \Delta Q_{i 2}+w_{3}^{*} \Delta Q_{i 3}+w_{4}^{*} \Delta Q_{i 4}+w_{5}^{*} \Delta Q_{i 5}
$$

2.4. Allocation of Carbon Quota Increment under the Improved Information Entropy Method. When using the information entropy method to allocate the carbon emission quota, the index with a significant influence degree is given a higher weight, otherwise, a smaller weight. The advantage of the entropy method is that it can overcome subjectivity and reduce the overlap of information among multiple indexes. However, it is easy to produce extreme value or duplication phenomenon in evaluation. In many studies, scholars use the multifactor mixed weighted information entropy distribution model to simulate the carbon emission quota distribution of each province under different scenarios in 2020 and then analyze and evaluate the results to find the optimal scheme [4]. In this study, the data were standardized to overcome the deviation. The improved entropy method, adding a time variable to determine the weight, is used in this 
paper to realize the comparison between different years. The steps are as follows:

(1) Select the $j$ indicator of $i$ province, expressed as $Z_{i j}$, and, by equation (19), standardize $Z_{i j}$ to get $Z_{i j}^{*}, i=1,2, \ldots, 30, j=1,2,3,4,5$ :

$$
Z_{i j}^{*}=\frac{Z_{i j}-Z_{\min }}{Z_{\max }-Z_{\min }}
$$

(2) The matrix $Z$ after the standardization of the five indicators is expressed as

$$
Z=\left[\begin{array}{ccccc}
Z_{11} & Z_{12} & Z_{13} & Z_{14} & Z_{15} \\
Z_{21} & Z_{22} & Z_{23} & Z_{24} & Z_{25} \\
\vdots & \vdots & \vdots & \vdots & \vdots \\
\vdots & \vdots & \vdots & \vdots & \vdots \\
Z_{i 1} & Z_{i 2} & Z_{i 3} & Z_{i 4} & Z_{i 5}
\end{array}\right] .
$$

(3) The proportion of the index $Z_{i j}^{*}$ is obtained by the following formula:

$$
R_{i j}=\frac{Z_{i j}^{*}}{\sum_{i=1}^{30} Z_{i j}^{*}},
$$

where $R_{i j}$ represents the proportion value of province $i$ for indicator $j$. The entropy of indicator $j, e_{j}$, is calculated by the formula above.

$$
e_{j}=-\frac{1}{\ln n} \sum_{i=1}^{30} R_{i j} \ln R_{i j}
$$

where $n$ represents the total number of provinces, $n=30$. The larger $e_{j}$ is, the less important it is in the integrated allocation and the smaller the weight is.

(4) According to formula (22), the coefficient of the difference of index $j$ is calculated as the following equation:

$$
g_{j}=1-e_{j}
$$

(5) Therefore, the smaller the entropy for the indicator is, the larger the index's weight is. The final weight for indicator $j$ with the IEM is obtained by the following equation, where $0<w j<1, \sum_{j=1}^{5} w_{j}^{*}=1$ :

$$
w_{j}=\frac{g_{j}}{\sum_{j=1}^{5} g_{j}} .
$$

Hence, the $\mathrm{CO}_{2}$ emissions increment quotas for province $i$ with the IEM are obtained. $\Delta Q_{i}$ is the increment of carbon quota in province $i$.

$$
\Delta Q_{i}=w_{1} \Delta Q_{i 1}+w_{2} \Delta Q_{i 2}+w_{3} \Delta Q_{i 3}+w_{4} \Delta Q_{i 4}+w_{5} \Delta Q_{i 5} .
$$

2.5. Main Calculation Process. The main idea of this paper is as follows: first, according to the collected data, carry out the preliminary operation to get all the data needed in this paper, and the data source is shown in Section 2.1. The predicted value of the permanent resident population, energy consumption, urban population, and the added value of the tertiary industry in 2030 are calculated using the Radial Basis Function (RBF) neural network, and the GDP is calculated using the growth rate. Then, through the calculation of each index under the single principle, the initial matrix is obtained. Use the methods shown in Section 2.3 to process the data to obtain the allocation weights under different methods, and then obtain the results of carbon quota allocation in 2030 under the two methods. Finally, by comparing the decline rate of the carbon intensity of each province under the two methods, the optimal allocation scheme is obtained. The flow chart of the calculation process is shown in Figure 1.

\section{Empirical Results}

3.1. Results of Carbon Emissions of Regions during 2005-2017. According to formula (1), the carbon emissions of each province from 2005 to 2017 are shown in Table 2. As shown in Table 2, there is a big gap in carbon emissions among different provinces from 2005 to 2017. From the average point of view, the largest carbon emissions province is Shandong, with 585.11 million tons, followed by Shanxi, Inner Mongolia, Hebei, Henan, and other provinces with large energy consumption and population, with carbon emissions of more than 400 million tons. On the contrary, the province with the smallest carbon emission is Hainan Province, which is only 21.36 million tons, while Qinghai Province is only 24.17 million tons. It can be seen that the difference between the highest and lowest carbon emissions is as high as 564 million tons. Overall, China's carbon emissions from principal energy consumption increased year by year from 2005 to 2017, which is inseparable from the rapid development of China's economy. With the promotion of China's carbon market in 2013, the growth of China's overall carbon emissions began to slow down. The total amount of carbon emission and the growth rate of carbon emission in China are shown in Figure 2. In 2013, the growth rate of carbon emission in most provinces began to decrease, among which the growth rate of national carbon emission was $-0.6 \%$, which became negative for the first time, indicating that the carbon market plays an essential role in promoting carbon emission reduction.

However, the imbalance of regional resource endowment and development leads to significant differences in carbon emission reduction rates in different regions. 


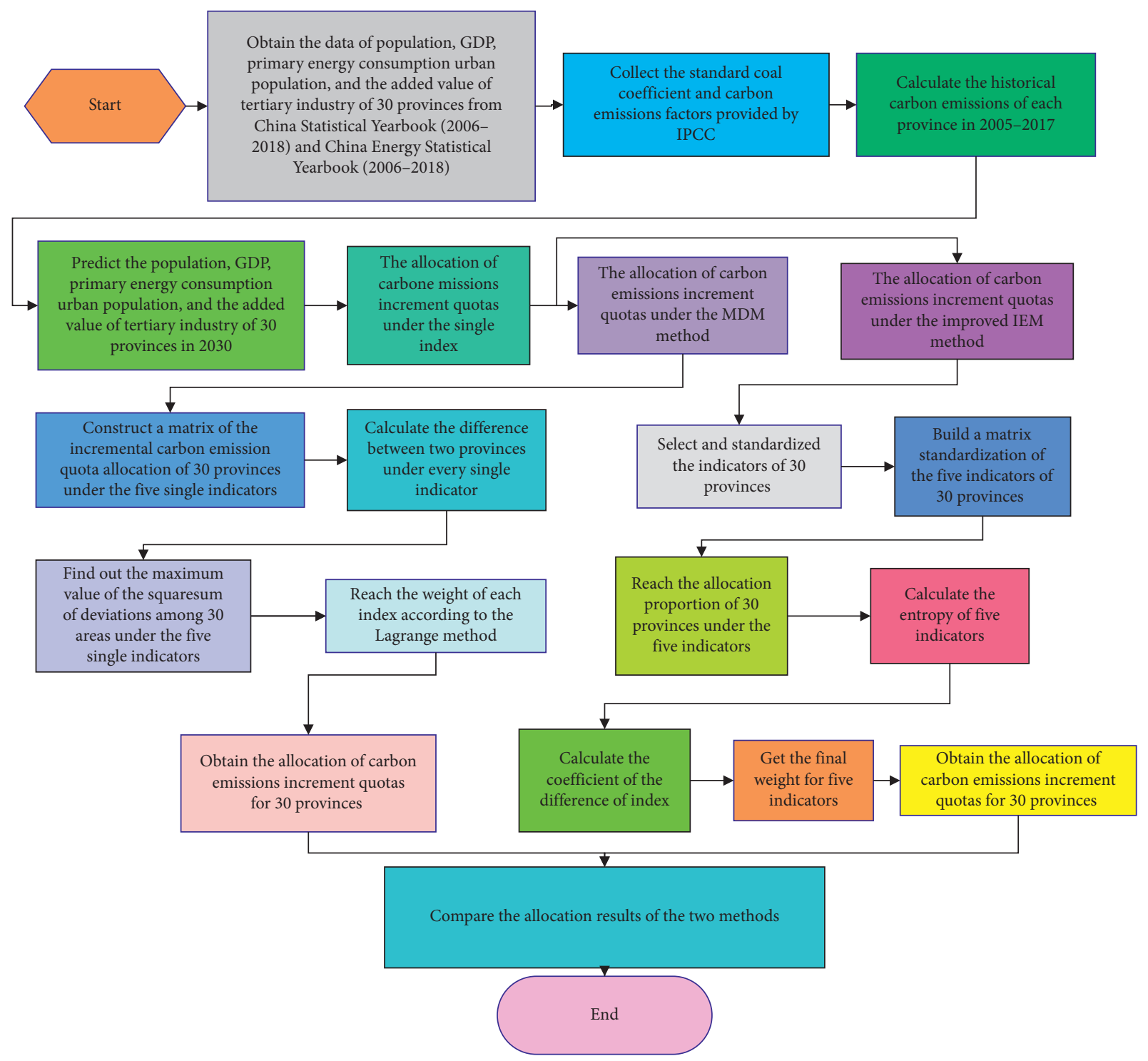

Figure 1: The flow chart of the calculation process.

Therefore, the design of a carbon quota allocation scheme suitable for different regional development needs is the basis for achieving the carbon emission reduction target in 2030.

3.2. Allocation Results under Five Single Principle. According to formulas (2)-(5), the total carbon emission of China in 2030 is 111.34 billion tons, and the increment of carbon quota $\Delta Q=55.68$ billion tons. Based on (6)-(10), the increment of carbon emission quota of each province under five single indicators in 2030 is calculated, as shown in
Table 3. It shows that, under the principle of equality, there is a high similarity in the carbon quota increment of regions with similar population size. Among them, six populous provinces, such as Hebei, Jiangsu, Shandong, Henan, Guangdong, and Sichuan, accounted for the increment of carbon quota of $5.39 \%, 5.88 \%, 7.20 \%, 7.06 \%, 7.73 \%$, and $6.11 \%$. While under the principle of efficiency, Hebei, Jiangsu, Zhejiang, Shandong, Henan, Guangdong, and Sichuan have a relatively large number of quotas, among which Jiangsu, Shandong, and Guangdong have an allowance of about $10 \%$. With the principle of feasibility, Hebei's 


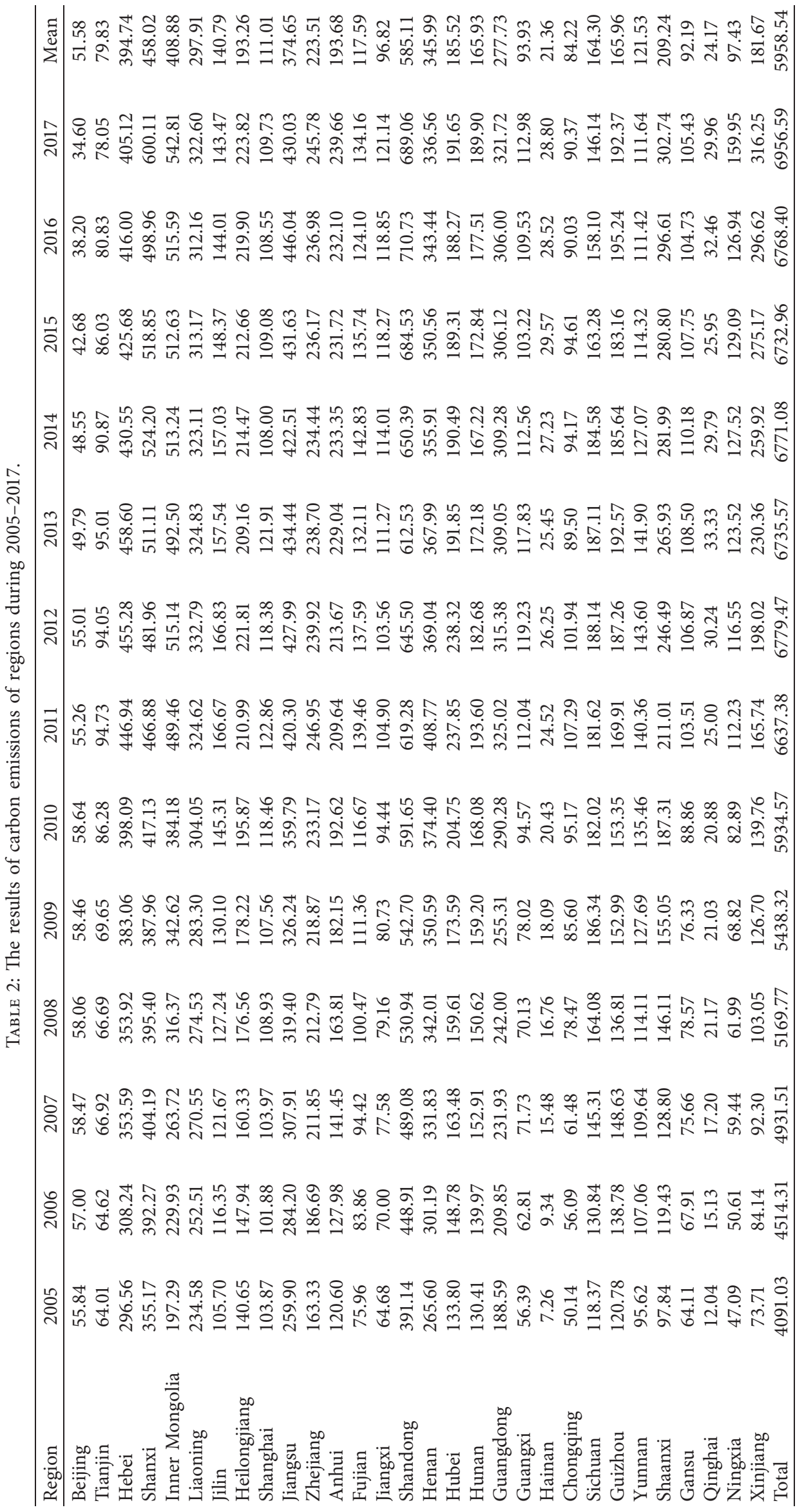




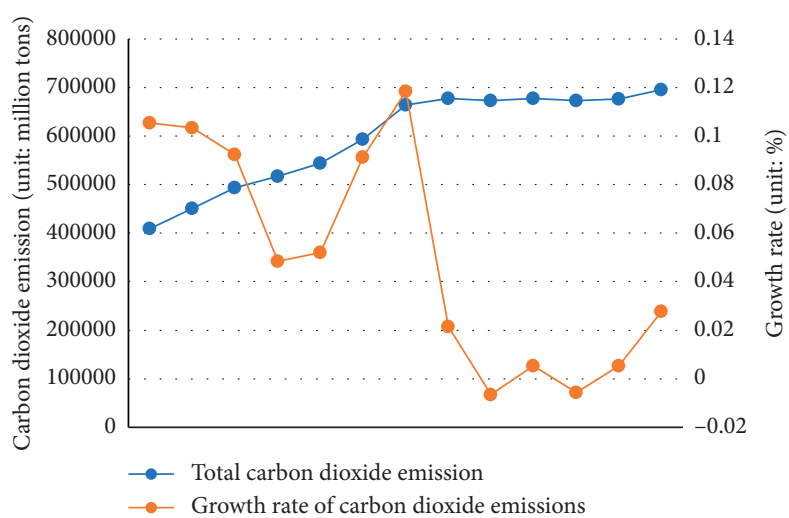

Figure 2: The total carbon emissions and the growth rate of carbon emissions.

carbon quota is as high as 7.75\%, which is inseparable from the transfer of Beijing and Tianjin industries to Hebei under the integration of Beijing, Tianjin, and Hebei. And Shanxi, Inner Mongolia, and Liaoning, which are primary energyproducing provinces, have a quota increment of $4.92 \%$, $5.88 \%$, and $5.04 \%$. The distribution of carbon emission quota under the principle of sustainable development is very similar to that under the population principle. According to the principle of innovation, the carbon quota of more developed regions such as Beijing, Tianjin, and Shanghai increased significantly, reaching 3.65\%, 2.90\%, and 5.73\%. Due to the difference in regional development and the imbalance of local carbon emissions, the allocation of carbon quota under any single indicator is natural to generate a sense of relative exploitation. China needs to design a reasonable regional carbon quota distribution scheme to reach the peak as soon as possible.

3.3. Allocation Results under the MDM Method. In this study, MATLAB is used to calculate the final weight of five indicators, as shown in Table 4. It shows that, under the MDM method, the GDP index and the proportion of tertiary industry index have a more considerable weight, followed by the historical carbon emission index.

According to formulas (11)-(16) and Table 3, the carbon quota distribution and proportion in each region can be calculated, as shown in Table 5. It is shown that the increment of carbon quota obtained by Guangdong is up to 507.01 million tons, followed by Shandong, Hebei, Jiangsu, and Henan, which, respectively, account for $8.1 \%, 5.16 \%$, 7.97\%, and 5.47\%. Hainan, Qinghai, and Ningxia have obtained smaller quotas, and the proportion of allowance is only $0.5 \%$. To make an exact spatial comparison, ArcGIS is used to create Figures 3 and 4 to compare the distribution results. According to Figure 3, the color gradually deepens with the increase of carbon emission quota increment. Under the five single principles, Hainan, Ningxia, and Qinghai, which have the lightest blue color, have the lowest quota, determined by their special development mode. The dark blue areas of Guangdong, Shandong, Hebei, Henan, Jiangsu, and Zhejiang have gained a lot of carbon quota increment, which is closely related to the energy consumption driven by the rapid economic development. Overall, the increment of carbon emission quota is gradually increasing from the eastern region to the western area. It is found that there is a significant gap in the carbon quota obtained by different areas under different distribution principles. Therefore, it is difficult to achieve fairness under a single indicator, which leads to a greater sense of relative exploitation in different regions. From Figure 4, we can find that areas with higher carbon emission quota increment under the MDM method are distributed in Guangdong, Jiangsu, Zhejiang, Hebei, and Shandong. At the same time, Henan and Sichuan have also obtained higher quota under the MDM method.

3.4. Allocation Results under the IEM Method. Use the improved information entropy method to obtain the dispersion of five indexes, as shown in Table 6. The entropy value of the population index is the largest $(0.9145)$, which shows that in 30 provinces, the dispersion degree of the population index is the smallest and relatively least important, so the minimum weight is given. On the contrary, the entropy value of the urbanization rate and the proportion of the tertiary industry are small, endowing a higher weight, as shown in Table 6.

According to formulas (17)-(22) and Table 6, the carbon emission quota and carbon intensity reduction rate 


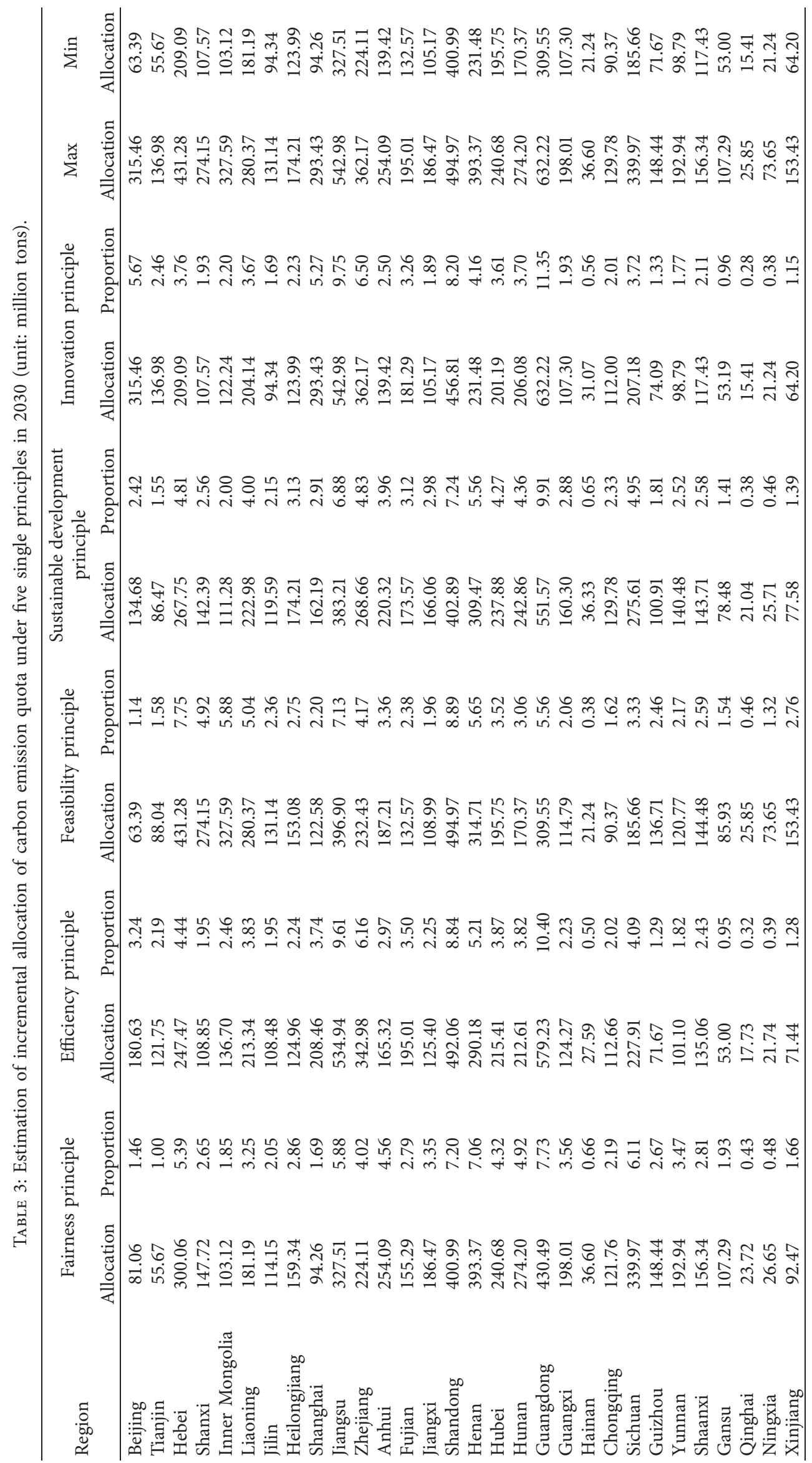


TABLE 4: The weights of the five indicators under the MDM method.

\begin{tabular}{lccccc}
\hline Weight & $\mathbf{w}_{1}$ & $\mathbf{w}_{2}$ & $\mathbf{w}_{3}$ & $\mathbf{w}_{4}$ & $\mathbf{w}_{5}$ \\
\hline MDM & 0.1863 & 0.2137 & 0.1901 & 0.1855 & 0.2243 \\
\hline
\end{tabular}

TABLE 5: Comparison of carbon quota allocation results between MDM and IEM methods.

\begin{tabular}{|c|c|c|c|c|c|c|}
\hline \multirow[b]{2}{*}{ Region } & \multicolumn{3}{|c|}{$\mathrm{MDM}$} & \multicolumn{3}{|c|}{ IEM } \\
\hline & $\begin{array}{c}\text { Allocation } \\
\text { (million tons) }\end{array}$ & $\begin{array}{l}\text { Proportion } \\
\text { (\%) }\end{array}$ & $\begin{array}{c}\text { The decline rate of carbon } \\
\text { intensity compared to } 2005 \\
(\%)\end{array}$ & $\begin{array}{c}\text { Allocation } \\
\text { (million tons) }\end{array}$ & $\begin{array}{c}\text { Proportion } \\
\text { (\%) }\end{array}$ & $\begin{array}{c}\text { The decline rate of carbon } \\
\text { intensity compared to } 2005 \\
(\%)\end{array}$ \\
\hline Beijing & 161.51 & 2.9 & 60.16 & 203.27 & 3.65 & 49.86 \\
\hline Tianjin & 99.9 & 1.79 & 76.83 & 161.63 & 2.9 & 62.52 \\
\hline Hebei & 287.36 & 5.16 & 85.59 & 252.49 & 4.53 & 87.34 \\
\hline Shanxi & 153.45 & 2.76 & 80.01 & 181.5 & 3.26 & 76.36 \\
\hline $\begin{array}{l}\text { Inner } \\
\text { Mongolia }\end{array}$ & 158.77 & 2.85 & 82.09 & 192.97 & 3.47 & 78.23 \\
\hline Liaoning & 219.82 & 3.95 & 67.83 & 217.15 & 3.9 & 68.22 \\
\hline Jilin & 112.73 & 2.02 & 77.67 & 146.4 & 2.63 & 71.00 \\
\hline Heilongjiang & 145.63 & 2.62 & 61.19 & 166.28 & 2.99 & 55.69 \\
\hline Shanghai & 181.33 & 3.26 & 68.17 & 209.6 & 3.76 & 63.21 \\
\hline Jiangsu & 443.7 & 7.97 & 73.66 & 319.01 & 5.73 & 81.06 \\
\hline Zhejiang & 290.33 & 5.21 & 65.42 & 238.8 & 4.29 & 71.56 \\
\hline Anhui & 190.42 & 3.42 & 79.01 & 179.99 & 3.23 & 80.16 \\
\hline Fujian & 168.68 & 3.03 & 77.77 & 173.27 & 3.11 & 77.16 \\
\hline Jiangxi & 136.67 & 2.45 & 78.36 & 146.6 & 2.63 & 76.79 \\
\hline Shandong & 451.19 & 8.1 & 80.98 & 331.77 & 5.96 & 86.01 \\
\hline Henan & 304.48 & 5.47 & 79.97 & 242.56 & 4.36 & 84.04 \\
\hline Hubei & 217.36 & 3.9 & 82.70 & 197.31 & 3.54 & 84.30 \\
\hline Hunan & 220.21 & 3.95 & 82.35 & 193.84 & 3.48 & 84.46 \\
\hline Guangdong & 507.01 & 9.11 & 57.89 & 332.5 & 5.97 & 72.38 \\
\hline Guangxi & 139.09 & 2.5 & 76.40 & 147.63 & 2.65 & 74.95 \\
\hline Hainan & 30.46 & 0.55 & 53.22 & 104.67 & 1.88 & -60.73 \\
\hline Chongqing & 113.15 & 2.03 & 83.06 & 144.68 & 2.6 & 78.34 \\
\hline Sichuan & 244.97 & 4.4 & 75.12 & 203.22 & 3.65 & 79.36 \\
\hline Guizhou & 104.31 & 1.87 & 89.51 & 137.62 & 2.47 & 86.16 \\
\hline Yunnan & 128.75 & 2.31 & 84.64 & 144.59 & 2.6 & 82.74 \\
\hline Shaanxi & 138.47 & 2.49 & 79.20 & 154.42 & 2.77 & 76.81 \\
\hline Gansu & 74.15 & 1.33 & 76.70 & 117.67 & 2.11 & 63.03 \\
\hline Qinghai & 20.49 & 0.37 & 79.27 & 87.86 & 1.58 & 11.09 \\
\hline Ningxia & 33.15 & 0.6 & 81.90 & 106.52 & 1.91 & 41.86 \\
\hline Xinjiang & 90.47 & 1.62 & 80.35 & 132.17 & 2.37 & 71.30 \\
\hline
\end{tabular}

of each province under MDM and IEM methods are obtained, as shown in Table 5. Under the information entropy method, Guangdong received the most carbon quota increment, up to 332.5 million tons. And Shandong, Jiangsu, Hebei, Henan, and Zhejiang also get a lot of carbon quota increment, which reached 331.77, 319.01, 252.49, 242.56, and 238.8 million tons, respectively. At the same time, Beijing and Shanghai have also allocated higher carbon quotas due to advanced technology. However, under the IEM method, compared with the target of carbon intensity in 2030, Beijing, Tianjin, Heilongjiang, Shanghai, and Gansu have not reached the goal for a $65 \%$ reduction of carbon intensity, while Hainan's carbon intensity has increased by $60.73 \%$ on the contrary. Meanwhile, the decrease rate of carbon intensity in Qinghai and Ningxia is only $11.09 \%$ and $41.86 \%$. Therefore, there are still many 

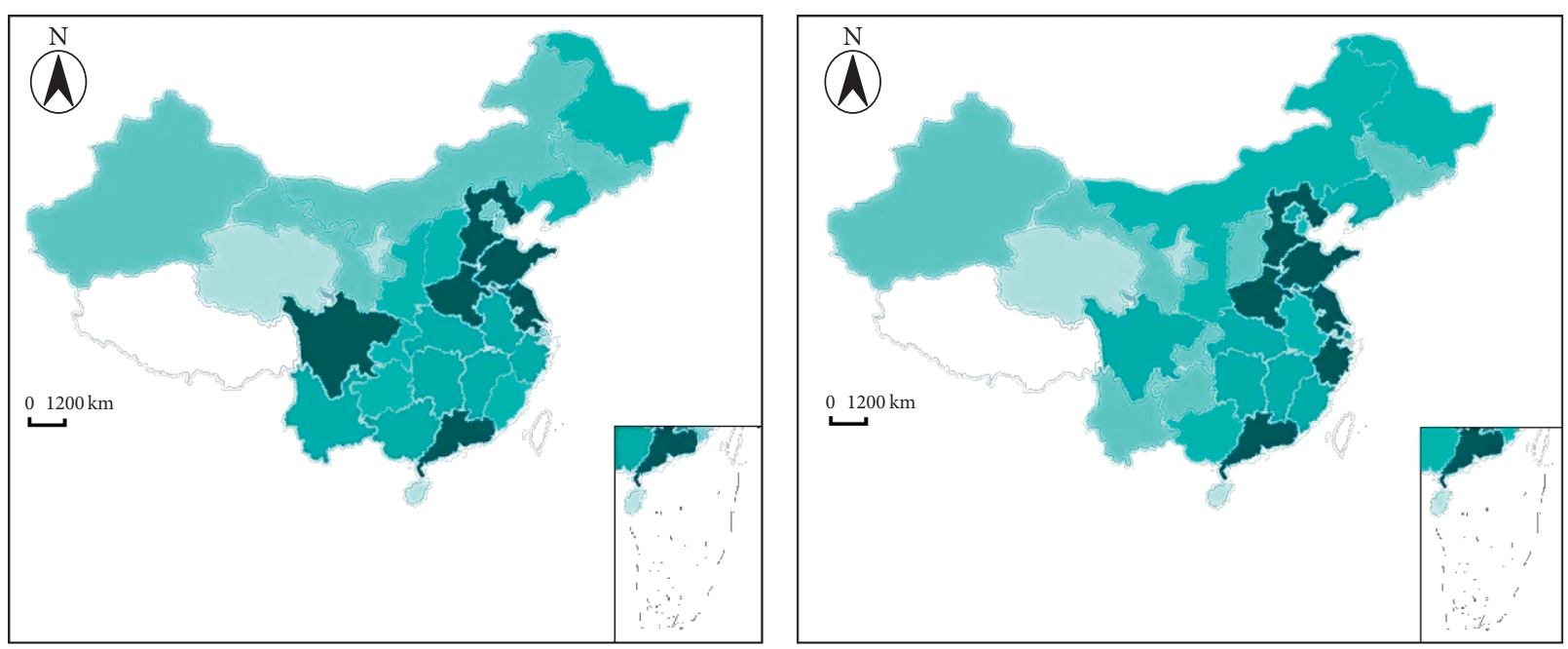
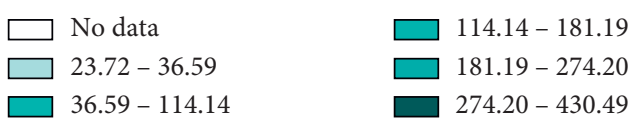

(a)

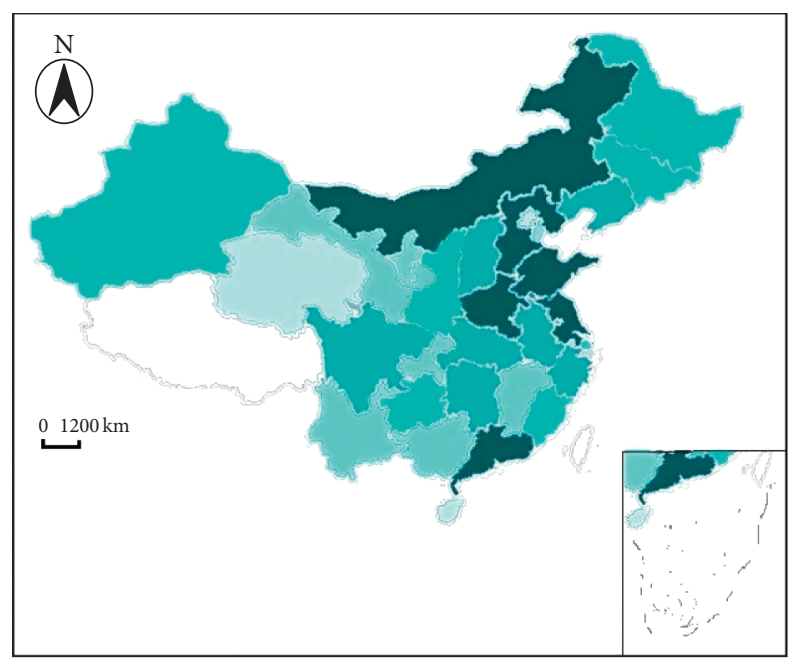

No data

$21.24-63.39$

$63.39-129.78$

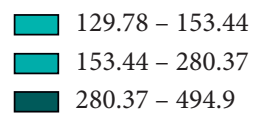

(c)

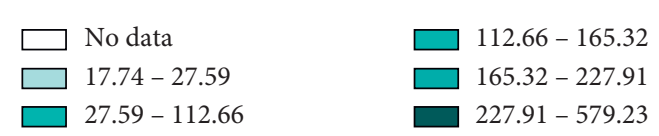

(b)

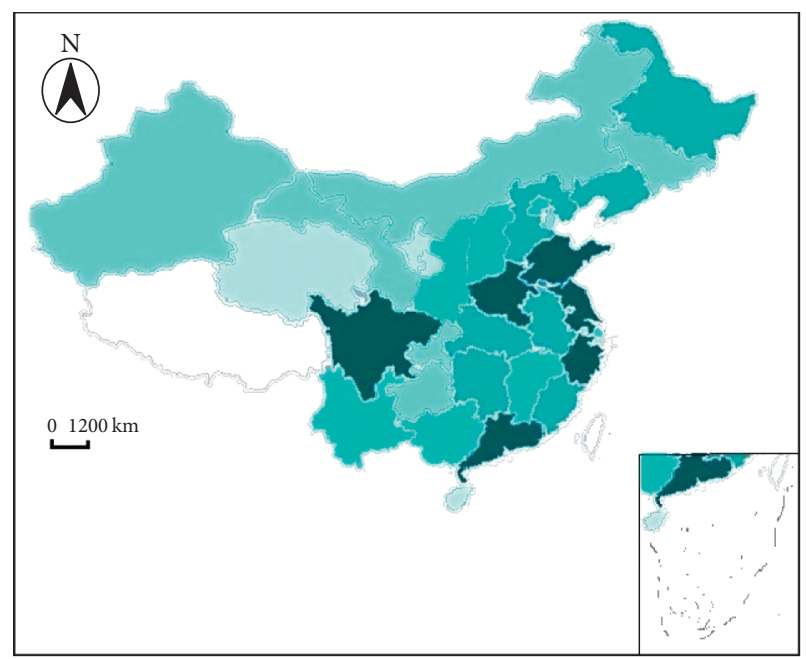

No data

$\square$ 21.04-36.33

$\square 36.33-129.78$

$\square$
$\square$
$\square \quad 166.06-267.75$ $\square 267.75-551.57$

(d)

Figure 3: Continued. 


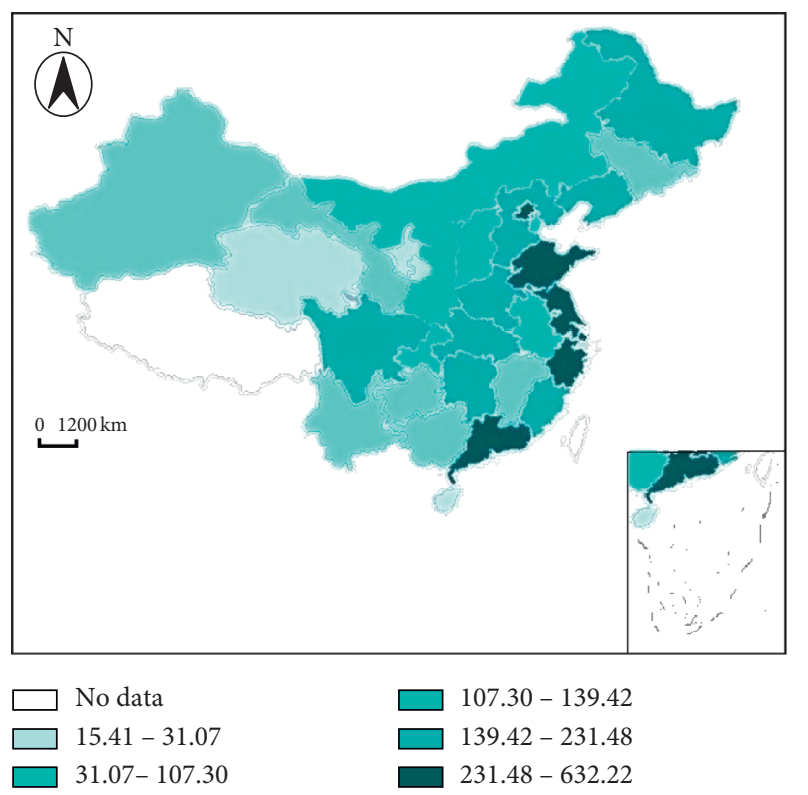

(e)

FIGURE 3: The comparison of the incremental allocation of carbon emission quota under five single principles. (a) Fairness principle. (b) Efficiency principle. (c) Feasibility principle. (d) Development principle. (e) Innovation principle.

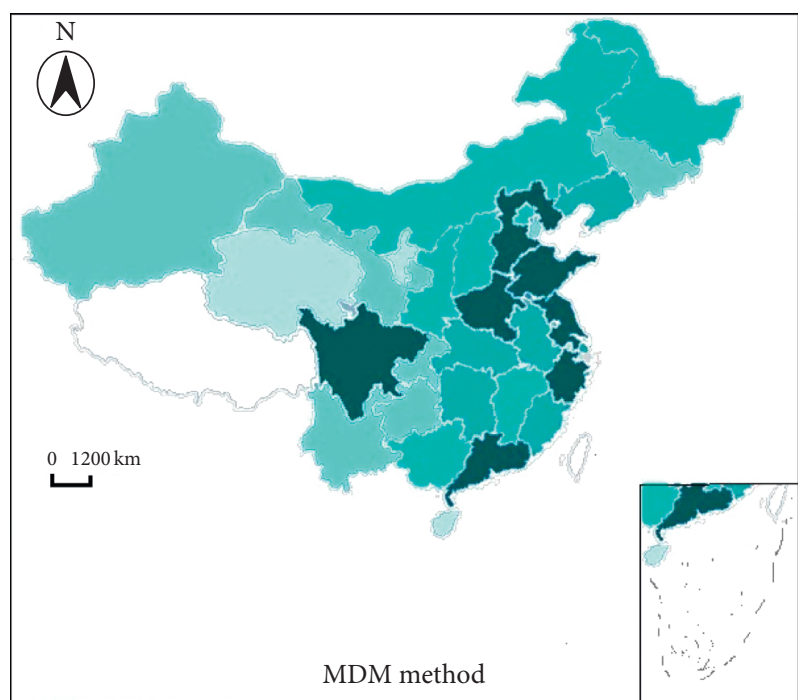

$\square$ No data
$\square \quad 20.49-33.15$
$\square 33.15-128.75$

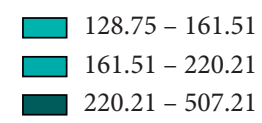

(a)
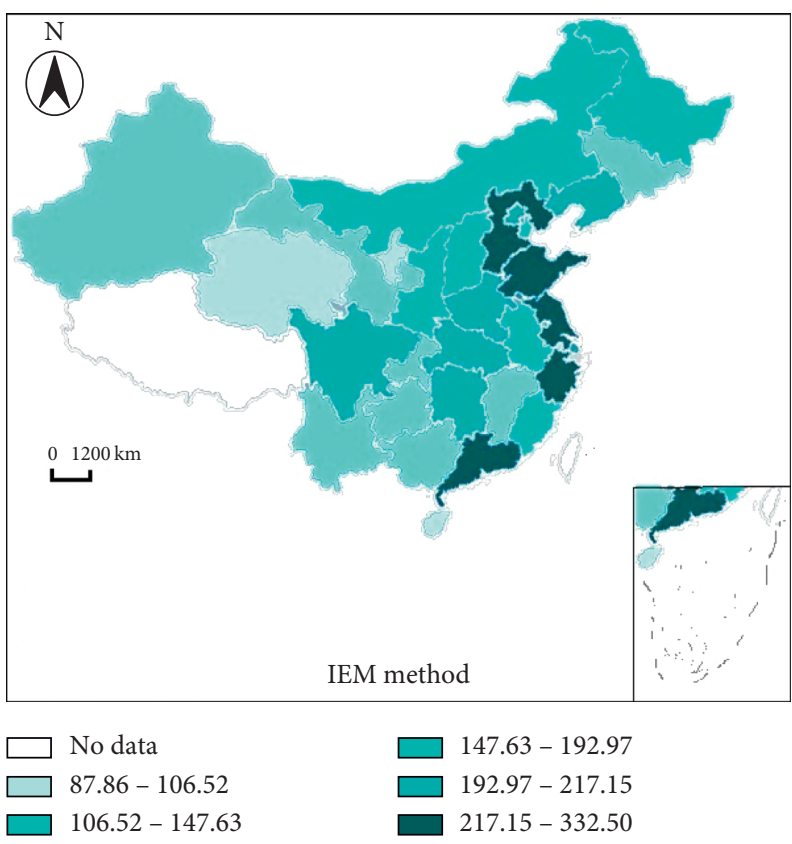

(b)

FIGURE 4: The comparison of incremental allocation of carbon emission quota under the MDM and IEM methods. (a) MDM method. (b) IEM method.

TABLE 6: The weights of the five indicators under the IEM method.

\begin{tabular}{lcccrr}
\hline Index & $\mathbf{w}_{1}$ & $\mathbf{w}_{2}$ & $\mathbf{w}_{3}$ & $\mathbf{w}_{4}$ & \\
\hline Weight & 0.1458 & 0.1801 & 0.2070 & 0.2352 & 0.2319 \\
Entropy & 0.9145 & 0.8943 & 0.8785 & 0.8620 & 0.8640 \\
\hline
\end{tabular}




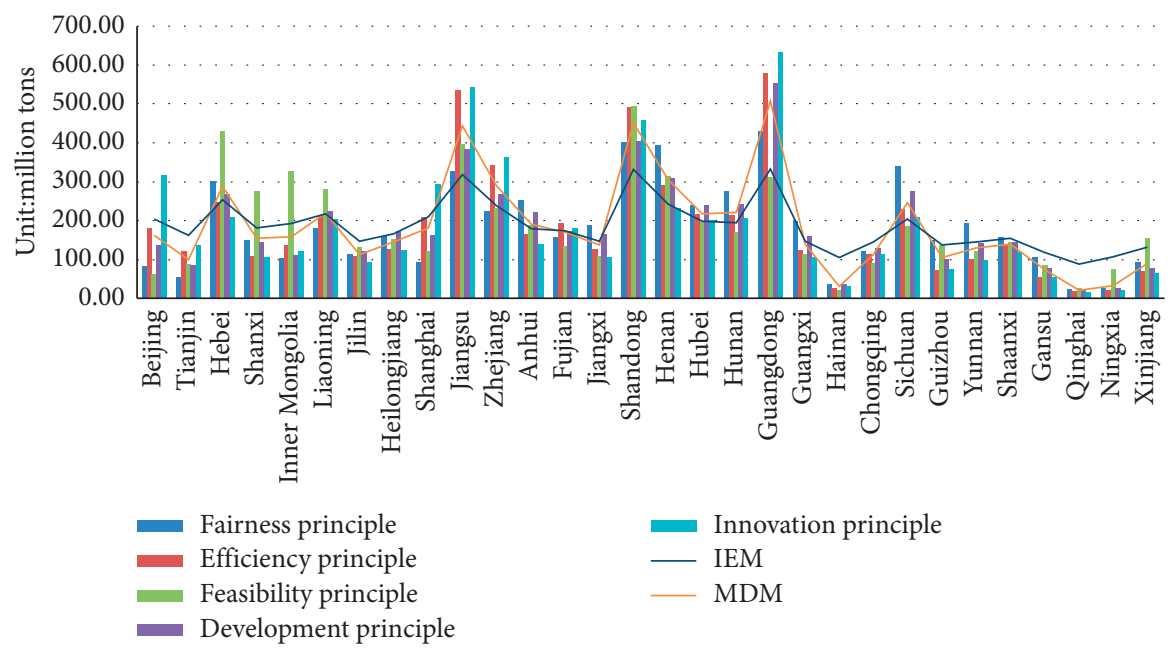

FIGURE 5: The comparison of the incremental allocation of carbon emission quota under three methods.

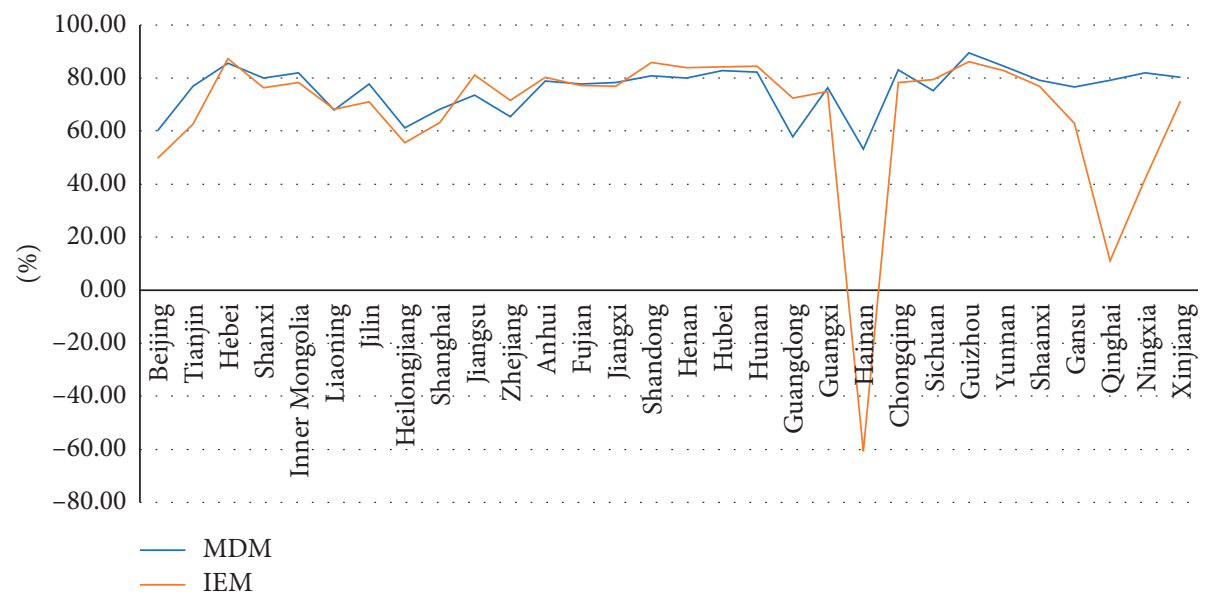

FIgURE 6: The carbon intensity reduction rate under MDM and IEM methods.

areas that can not reach the carbon emission reduction target in 2030 by the IEM method.

\section{Conclusions and Discussion}

4.1. Conclusions. Based on the perspective of a single index and comprehensive index analysis, this paper uses MDM and IEM methods to study the carbon emission quota allocation of provinces in China under the comprehensive weighting method of five principles. Figures 5 and 6 are drawn combined with the data in Tables 3 and 5 to make a more clear and intuitive comparison. The main conclusions are as follows:

(1) Under a single indicator, there are significant differences in carbon quota allocation among provinces. Taking Beijing as an example, under the principle of fairness and feasibility, its carbon quota incremental allocation only accounts for $1.46 \%$ and $1.14 \%$ of the national total, while, under the principle of innovation, its allocation amount is as high as
315.46 million tons, accounting for $5.67 \%$ of the national total. That is due to Beijing's high level of scientific and technological development and its emphasis on technological innovation. It is not difficult to see that, under a single indicator, the distribution of different provinces is quite different, and it is easy to produce a strong sense of deprivation. Therefore, a single indicator can not achieve a reasonable allocation of carbon quotas.

(2) Under the MDM method, Guangdong, Shandong, Jiangsu, Henan, and Hebei obtained a larger quota allocation increment, accounting for $9.11 \%, 8.1 \%$, $7.97 \%, 5.47 \%$, and $5.16 \%$ of the national carbon quota allocation, respectively. Hainan, Ningxia, and Qinghai have the smallest quota, accounting for only $0.55 \%, 0.6 \%$, and $0.37 \%$ of the national quota related to the development stage of each region. The distribution result is consistent with Yang [23]. Under the MDM method, the decline rate of carbon intensity in each region is relatively high. Only 
Guangdong and Hainan have a decrease of less than $60 \%$, but both of them are higher than $50 \%$. Therefore, using this method, the carbon emission reduction target of 2030 years can be better achieved.

(3) According to the IEM method, the gap between different regions in carbon quota allocation becomes smaller. The province with the highest quota is Guangdong, which is as high as 332.5 million tons. And the province with the lowest quota is Hainan, which gets 104.67 million tons. By comparison, it is found that some provinces are prone to overallocation or underallocation with this method, and the carbon intensity reduction rate of Beijing, Qinghai, Ningxia, and Gansu is far below 60\%, among which the carbon intensity of Hainan has increased instead.

4.2. Discussion. Although it is concluded that the MDM method is more conducive to achieve the goal of carbon emission reduction in 2030 through the comparative analysis of a variety of methods, there are still some shortcomings in this paper. Firstly, factors such as the slowdown of GDP growth and the reduction of $\mathrm{CO}_{2}$ emissions caused by the epidemic of COVID-19 are not taken into account. Secondly, in selecting the five principle indicators, no more detailed secondary indicators are set, which tends to make the estimated results less stable. Finally, the national policy control factors are not considered, such as whether the Yellow River Basin, the Yangtze River Delta, Beijing-TianjinHebei, and other hot spots have the right to priority quota. It is necessary to explore the above aspects in the future to put forward a more reasonable carbon quota allocation scheme.

\section{Policy Recommendations}

Based on the above results, the reasonable allocation of carbon quota allocation is the key to achieve the carbon emission reduction target in 2030. This paper puts forward the following policy recommendations.

At the national level, we should fully consider the unbalanced regional development characteristics and should not achieve the same reduction range of carbon intensity in each region. Therefore, we need to specify the principle of "common but differentiated responsibilities." Therefore, in allocating carbon quota, we should fully consider the principle of fairness, efficiency, feasibility, sustainable development, and innovation to make the allocation results more balanced and realize the coordinated development of different regions.

At the regional level, the eastern region as the principal energy consumption area has a higher economic level, so it should take more responsibility for carbon emission reduction. Carbon emission quota subsidies should be given appropriately to ensure the economic development of resource-based areas such as Inner Mongolia, Shanxi, and Shaanxi. Technologically, developed regions should attach importance to technological innovation, adopt more clean technologies, develop green innovation, and accelerate economic transformation. They should also take the initiative to assume more responsibility for carbon emission reduction, allocate part of the carbon quota to less developed regions, promote their economic growth, and realize regional coordinated development.

As carbon emission permits are fundamentally scarce resources, they play a significant role in economic development. If the allocation of carbon quota is unreasonable, there are fateful conflicts among regions. Therefore, decision-makers should improve the relevant system of the carbon market as soon as possible. A dynamic carbon quota allocation scheme should be formulated. Preallocation should be done according to the development needs of different regions. The preallocation should be adjusted, and $t$ secondary allocation should be carried out according to the differences timely to achieve a relatively harmonious state and ensure the stable and practical realization of China's carbon emission reduction target in 2030 .

\section{Data Availability}

The data used to support the findings of this study are included within the article.

\section{Conflicts of Interest}

The author declares no conflicts of interest.

\section{Authors' Contributions}

Yuan Zhang mainly designed the structure and research methods of the paper and the writing of the full text.

\section{Acknowledgments}

This research was financed by the Natural Science Foundation of China Project (Grant no. 51708310).

\section{References}

[1] B. Dudley, B. P. Statistical Review of World Energy 2018, British Petroleum Company, London, UK, 2018.

[2] J. Chen, "An empirical study on China's energy supply-anddemand model considering carbon emission peak constraints in 2030," Engineering, vol. 3, no. 4, pp. 512-517, 2017.

[3] The 13th five-year plan for energy development. http://www. ndrc.gov.cn/zcfb/zcfbtz/201701/t20170117_835278.html.

[4] X. Zhou, X. Guan, M. Zhang, Y. Zhou, and M. Zhou, "Allocation and simulation study of carbon emission quotas among China's provinces in 2020," Environmental Science and Pollution Research, vol. 24, no. 8, pp. 7088-7113, 2017.

[5] D. Y. Song and X. P. Liu, "Spatial distribution of provincial carbon emissions," China Population Resources and Environment, vol. 23, no. 5, pp. 7-13, 2013.

[6] F. Dong, R. Long, B. Yu et al., "How can China allocate CO2 reduction targets at the provincial level considering both equity and efficiency? evidence from its Copenhagen accord pledge," Resources, Conservation and Recycling, vol. 130, pp. 31-43, 2018.

[7] J. K. Song, L. Liang, and D. P. Niu, "The allocation of carbon emission rights in the province of China-based on environmental FCAM," Technol. Econ.vol. 10, pp. 100-106, 2017. 
[8] P. Zhou, Z. R. Sun, and D. Q. Zhou, "Optimal path for controlling $\mathrm{CO}_{2}$ emissions in China: a perspective of efficiency analysis," Energy Economics, vol. 45, pp. 99-110, 2014.

[9] K. Wang, X. Zhang, Y.-M. Wei, and S. Yu, "Regional allocation of $\mathrm{CO}_{2}$ emissions allowance over provinces in China by 2020," Energy Policy, vol. 54, pp. 214-229, 2013.

[10] Z. Miao, Y. Geng, and J. Sheng, "Efficient allocation of $\mathrm{CO}_{2}$ emissions in China: a zero sum gains data envelopment model," Journal of Cleaner Production, vol. 112, pp. 41444150, 2016.

[11] Y.-J. Zhang and J.-F. Hao, "Carbon emission quota allocation among China's industrial sectors based on the equity and efficiency principles," Annals of Operations Research, vol. 255, no. 1-2, pp. 117-140, 2017.

[12] S. Yu, Y.-M. Wei, and K. Wang, "Provincial allocation of carbon emission reduction targets in China: an approach based on improved fuzzy cluster and Shapley value decomposition," Energy Policy, vol. 66, pp. 630-644, 2014.

[13] Y.-J. Zhang, A.-D. Wang, and Y.-B. Da, "Regional allocation of carbon emission quotas in China: evidence from the Shapley value method," Energy Policy, vol. 74, pp. 454-464, 2014.

[14] Z. Liao, X. Zhu, and J. Shi, "Case study on initial allocation of Shanghai carbon emission trading based on Shapley value," Journal of Cleaner Production, vol. 103, pp. 338-344, 2015.

[15] W. Chen and Q. He, "Intersectoral burden sharing of $\mathrm{CO}_{2}$ mitigation in China in 2020," Mitigation and Adaptation Strategies for Global Change, vol. 21, no. 1, pp. 1-14, 2016.

[16] J. Zhou, Y. Li, X. Huo, and X. Xu, "How to allocate carbon emission permits among China's industrial sectors under the constraint of carbon intensity?" Sustainability, vol. 11, no. 3, pp. 914-934, 2019.

[17] P. Zhou, L. Zhang, D. Q. Zhou, and W. J. Xia, "Modeling economic performance of interprovincial $\mathrm{CO}_{2}$ emission reduction quota trading in China," Applied Energy, vol. 112, pp. 1518-1528, 2013.

[18] H. L. Mu, X. Han, and H. X. Zhao, " $\mathrm{CO}_{2}$ abatement allocation among different provinces of China based on MACC," Applied Mechanics and Materials, vol. 675-677, pp. 1869-1874, 2014.

[19] Y. Chen and S. Lin, "Decomposition and allocation of energyrelated carbon dioxide emission allowance over provinces of China," Natural Hazards, vol. 76, no. 3, pp. 1893-1909, 2015.

[20] J.-W. Park, C. U. Kim, and W. Isard, "Permit allocation in emissions trading using the Boltzmann distribution," Physica A: Statistical Mechanics and Its Applications, vol. 391, no. 20, pp. 4883-4890, 2012.

[21] R. Han, B.-J. Tang, J.-L. Fan, L.-C. Liu, and Y.-M. Wei, "Integrated weighting approach to carbon emission quotas: an application case of Beijing-Tianjin-Hebei region," Journal of Cleaner Production, vol. 131, pp. 448-459, 2016.

[22] J. B. LI, Z. Q. Zhang, and Y. L. Xiong, "Analysis of China's provincial carbon dioxide emission spatiotemporal pattern," Economic Geography, vol. 34, no. 9, pp. 158-165, 2014.

[23] C. Yang, L. Wu, J. Li et al., "Distribution of carbon emission rights in China based on equity perspective," Resource Science, vol. 41, no. 10, pp. 1801-1813, 2019.

[24] Q. Huang and X. Zhao, "Allocation of carbon dioxide emission reduction targets in China based on the improved equal proportion distribution," Journal of Arid Land Resources and Environment, vol. 1, no. 33, pp. 1-8, 2019.

[25] L. Li, Y. Li, F. Ye, and L. Zhang, "Carbon dioxide emissions quotas allocation in the pearl river delta region: evidence from the maximum deviation method," Journal of Cleaner Production, vol. 177, pp. 207-217, 2018.

[26] Y. Wang, H. Zhao, F. Duan, and Y. Wang, "Initial provincial allocation and equity evaluation of China's carbon emission rights-based on the improved TOPSIS method," Sustainability, vol. 10, no. 4, p. 982, 2018.

[27] Y. Li, Z. Li, M. Wu, F. Zhang, and G. De, "Regional-level allocation of $\mathrm{CO}_{2}$ emission permits in China: evidence from the Boltzmann distribution method," Sustainability, vol. 10, no. 8 , p. 2612, 2018.

[28] Q. Lv, D. H. Liu, and H. Liu, "Effects of urbanization on freight transport carbon emissions in China: common characteristics and regional disparity," Journal of Cleaner Production, vol. 211, pp. 481-489, 2019.

[29] P. Zhou and M. Wang, "Carbon dioxide emissions allocation: a review," Ecological Economics, vol. 125, pp. 47-59, 2016.

[30] A. Rose, "Reducing conflict in global warming policy," Energy Policy, vol. 18, no. 10, pp. 927-935, 1990.

[31] Y.-M. Wei, L. Wang, H. Liao, K. Wang, T. Murty, and J. Yan, "Responsibility accounting in carbon allocation: a global perspective," Applied Energy, vol. 130, no. 130, pp. 122-133, 2014.

[32] P. Bohm and B. Larsen, "Fairness in a tradeable-permit treaty for carbon emissions reductions in Europe and the former Soviet Union," Environmental \& Resource Economics, vol. 4, no. 3, pp. 219-239, 1994.

[33] H. Q. Qian, L. B. Wu, and F. Z. Ren, "From"whipping fast cattle"to efficiency drive: a study on the allocation mechanism of carbon emission rights between regions in China," Economic Research, vol. 3, pp. 86-102, 2019.

[34] G. Phylipsen, J. Bode, K. Blok, H. Merkus, and B. Metz, “A triptych sectoral approach to burden differentiation; GHG emissions in the European bubble," Energy Policy, vol. 26, no. 12, pp. 929-943, 1998.

[35] G. Fan, M. Su, and J. Cao, "Economic analysis of final consumption and carbon emission reduction responsibility," Economics of China, vol. 158, no. 1, pp. 50-55, 2010.

[36] L. Chang and X. Hao, "Carbon emission performance and quota allocation in the bohai rim economic circle," Journal of Cleaner Production, vol. 258, p. 258, 2020.

[37] IPCC, Climate Change 2014: Mitigation of Climate Change, Cambridge University Press, Cambridge, UK, 2014.

[38] C. Zhou, S. Wang, and J. Wang, "Examining the influences of urbanization on carbon dioxide emissions in the Yangtze River Delta, China: kuznets curve relationship," Science of the Total Environment, vol. 675, pp. 472-482, 2019.

[39] Z. Wang, C. Cui, and S. Peng, "How do urbanization and consumption patterns affect carbon emissions in China? A decomposition analysis," Journal of Cleaner Production, vol. 211, pp. 1201-1208, 2019.

[40] Y. Li, R. Zhao, T. Liu, and J. Zhao, "Does urbanization lead to more direct and indirect household carbon dioxide emissions? evidence from China during 1996-2012," Journal of Cleaner Production, vol. 102, 2015.

[41] Y. Yuan, Q. M. Xi, T. S. Sun et al., "The impact of the industrial structure on regional carbon emission: empirical evidence across countries," Geographical Research, vol. 35, no. 1, pp. 82-94, 2016.

[42] C. Q. Tao, Y. Z. Peng, and Z. X. Ju, "An empirical study on economic growth, industrial structure and the carbon emissions: based on PVAR model," Economic Survey, vol. 32, no. 4, pp. 126-131, 2015. 